\title{
PERCEIVED BODY IMAGE AND ITS RELATIONSHIP WITH BODY MASS INDEX, SELF-ESTEEM, BODY CHANGE STRATEGY, AND SOCIAL NETWORK USAGE AMONG RURAL ADOLESCENTS IN SARAWAK, MALAYSIA
}

\author{
Wong Liang Tung ${ }^{1}$ and Md Mizanur Rahman ${ }^{1}$ \\ ${ }^{1}$ Faculty of Medicine and Health Sciences, Universiti Malaysia Sarawak, 94300 Kota Samarahan, Sarawak, Malaysia \\ Corresponding author: Md Mizanur Rahman \\ Email: rmmizanur@unimas.my; alf_wlt@hotmail.com
}

\begin{abstract}
Body image is a complex and multifaceted construct with multiple associated factors determining its perception among adolescents. This study aimed to determine the perceived body image and its relationship with body mass index, selfesteem, body change strategy, and social network usage among rural adolescents. This study was a cross-sectional study design using a multistage random sampling technique to select adolescents aged 10 to 19 years. A total of 318 adolescents' data were collected using a self-administered questionnaire. Data analysis was done using SPSS version 22.0 with a $p$-value of $<0.05$ was considered statistically significant. The mean (SD) age of adolescents was 14.6 (2.7) years with a male and female ratio of 1.09:1. The mean score (SD) of perceived body image was 3.63 (0.87). Multiple linear regression analysis revealed that gender, body mass index, and strategy to increase weight could predict perceived body image among adolescents. However, self-esteem did not correlate with perceived body image. Although, the body image dissatisfaction level was low among rural adolescents compared to other studies in Malaysia. However, it can still pose a threat to adolescents' health if not addressed accordingly.
\end{abstract}

Keywords: Body image, Body change strategy, Self-esteem, Social network usage, Sarawak, Malaysia

\section{INTRODUCTION}

Body image is a person's perceptions, thoughts, and feelings about his or her body ${ }^{1}$. It is a complex and multifaceted construct ${ }^{2}$, which can be examined through various elements, such as appearance satisfaction and appearance orientation ${ }^{3}$. Body image is closely related to adolescents' growth and development ${ }^{4}$. During the adolescence phase, adolescents are subjected to physical, cognitive, psychosocial, and social developments. These developments can result in either body image satisfaction or body image dissatisfaction ${ }^{5}$.

Male and female adolescents generally have different body image preferences. Males typically prefer muscular body size and shape, while females usually sought for body thinness ${ }^{6-10}$. Body image preferences among adolescents can be caused by various factors such as peer pressure, media influences, and celebrities influence ${ }^{11}$. These factors, especially media influences, usually portray females having thin body figures and males with muscular body shape. As such, adolescents who do not have the portrayed body image may become dissatisfied with their body image.

In Malaysia, previous studies had been done to assess perceived body image among secondary school students 12-17. The prevalence of adolescents who were dissatisfied with their body image was between $33 \%$ and $78 \%$. These studies also found that a higher percentage of female adolescents were dissatisfied with their body as compared to male adolescents. The highest percentage of body image dissatisfaction was reported previously ${ }^{13}$, whereby up to $82 \%$ of its female respondents were found to have body image dissatisfaction. Similar findings were reported among Japanese and $77.2 \%$ of Finnish adolescents ${ }^{18}$.

Body image dissatisfaction is sometimes dangerous. It is associated with disordered eating behaviours, unhealthy weight control behaviours, low physical activity, exercise, lower self-esteem, and suicidal ideation 19-26. By identifying the factors associated with perceived body image, relevant authorities would address this issue among adolescents accordingly. Apart from peers, celebrities, and media influence body image ${ }^{11}$, there are other factors associated with perceived body image. These factors include body mass index, self-esteem, and social network usage ${ }^{26-28}$.

Body mass index (BMI) measures a person's nutritional status and overall body size and shape 29. Male adolescents with normal BMI were found to be more satisfied with their body image as compared to underweight or overweight counterpart ${ }^{30}$. On the other hand, female adolescents who were underweight are more satisfied with their body image than normalweight and overweight female adolescents. Abdul Latif et al. ${ }^{31}$ found that almost $80 \%$ of the overweight adolescents were dissatisfied with their body image while less than $60 \%$ of normalweight and underweight adolescents had body 
image dissatisfaction. However, Canpolat et al. ${ }^{32}$ found contradicting results whereby all BMI groups had similar body image satisfaction levels among adolescents. As such, this study aims to determine the relationship between perceived body image and BMI among adolescents.

Self-esteem is the degree to which a person holds his or her acceptance or rejection attitudes toward him or herself ${ }^{33}$. Self-esteem is often associated with body image $26,34,35$. A majority of the studies determined that current perceived body image can predict future self-esteem ${ }^{26,36-38}$. However, previous studies were able to determine that self-esteem can predict future perceived body image 26,39 .

Social networking is used to communicate with people who share your interests using a website or other service on the internet ${ }^{40}$. Widely available modern technology, peoples have access to the internet, adolescents are much easier to be influenced by the content they view on various social network platforms ${ }^{41,27}$. Social networking can cause adolescents to develop body image dissatisfaction through social comparison with friends and celebrities 42,43 . As rural adolescents also started to have access to the internet, they too are prone to be influenced by content on social networks.

Body change strategies are methods used by a person with body image dissatisfaction to improve his or her body image ${ }^{44}$. The commonly used body change methods are excessive exercise, disordered eating behaviours, and medication use 27,45. A few studies in Malaysia assess the disordered eating behaviour among adolescents 12,17 . One study in Malaysia surveyed the muscle increasing strategies used by adolescents to improve body image, especially among males ${ }^{46}$. All these studies conducted among urban adolescents do not represent the rural population, which may have different body change strategies. This research also aims to provide a more in-depth understanding of the body change strategies used by rural adolescents and the relationship with perceived body image.

\section{METHODS}

\section{Study setting}

This cross-sectional study was designed to collect information on perceived body image, BMI, selfesteem, body change strategy, and social network usage among rural adolescents in Samarahan and Asajaya districts of Sarawak. The study was conducted from September 2019 until August 2020. The inclusion criteria were mentally sound adolescents aged between 10 and 19, irrespective of gender, staying in Samarahan and Asajaya districts.

Ministry of Rural Development defined rural areas as areas outside of town areas gazetted by the
Department of Statistics Malaysia and areas not under local councils' authority. The list of rural villages was obtained from Samarahan and Asajaya District Office, respectively. There are a total of 50 rural villages from Samarahan district and 49 rural villages from Asajaya district.

\section{Data collection instruments and procedure}

The current sample size was calculated using a single proportion formula. With the anticipated prevalence of $78 \%{ }^{13}$, confidence interval of $95 \%$, and a non-response rate of $20 \%$, the minimum sample size required was 316 . The sampling procedure was based on a multistage sampling approach. The decision on the total respondents for each selected rural village was based on population proportion. Malaysia population census found that adolescents are representing $20 \%$ of the total population ${ }^{47}$. As such, this study chose to select 16 respondents to represent each selected rural village. For the selection of villages, the villages were arranged in alphabetical order for each district. The selection of villages from the lists started with a random number, followed by every 5 th interval. Ten villages were selected from each district to reach the sample size of 316 adolescents. Data was collected using a self-administered questionnaire consisting of five parts: Part A: Demographics; Part B: BMI and social network usage; Part C: Perceived body image; Part D: Body change strategy; and Part E: Self-esteem.

\section{Measurements}

Perceived Body Image was assessed using 10 Likert-scale questions. These items were adopted and translated from Body Image Concern subsection of Body Image and Body Change Questionnaire (BIBCQ) ${ }^{48}$. The scale consists of five rating score ranging from one (1) "extremely dissatisfied" to five (5) "extremely satisfied". An overall mean score of perceived body image used for statistical analysis. The higher mean score would indicate that more respondents are satisfied with their body image.

Body Mass Index was calculated by measuring respondents' body weight and height. Bodyweight was measured using a portable weighing scale. The respondents were asked to remove their shoes before measurement. Weight was taken to the nearest $0.1 \mathrm{~kg}$. Body height was measured against a stadiometer with stand upright with heels and occiput against the stadiometer looking straight ahead. Frankfurt plane (straight line between the lower border of eye orbit and upper margin of external auditory meatus) was ensured to be horizontal and perpendicular to the body initial height measurement being taken. Height was taken to the nearest $0.1 \mathrm{~cm}$.

Self-esteem was assessed using 10 Likert-scale questions. These items were adapted from Rosenberg Self-esteem scale ${ }^{33}$. It has five positively worded items and five negatively 
worded items. The scale consists of four rating score ranging from zero $(0)$ "strongly disagree" to three (3) "strongly agree". Reverse scoring was used for negative items. The translated Malay version of the scale was used ${ }^{49}$. An overall summative score of self-esteem was used for statistical analysis.

Body Change Strategy consists of six sub-sections, namely food practices, food supplements, strategies to lose weight, strategies to increase weight, strategies to increase muscle tone, and strategies to increase muscle size. These items were adopted and translated from respective subsections of Body Image and Body Change Questionnaire (BIBCQ) ${ }^{48}$. Food practices assess respondents' binge eating behaviours; food supplements assess respondents' usage of diet pills or steroids for body change; strategies to lose weight, increase weight, increase muscle tone, and increase muscle size assess respondents' change in eating habit and usage of exercise for body change in the respective sub-sections. Each sub-section consists of 6-10 Likert-scale questions 48 . The scale consists of five rating score ranging from one (1) "always" to five (5) "never". An overall mean score of each sub-section was calculated for statistical analysis. The high mean score would indicate respondents were less likely to practice respective strategies for body change.

Social network usage was assessed using one question. The respondents were given seven options, i.e., "Facebook," “Instagram," "YouTube," "Messengers," “Twitter," "Pinterest", and "others" to choose from, and were allowed to choose multiple options. The total number of social network uses were calculated for statistical analysis.

The questionnaire was initially developed in the English version. Next, it was translated into Malay version by two translators whose mother tongue is the Malay language. After combining both the Malay version, the questionnaire was backtranslated into an English version. The finalised Malay version proceeded for Pre-test.

\section{Pre-test}

A questionnaire pre-test had been performed in two rural villages, one from each district. Both of these villages are in the non-sampled area. A total of 36 respondents participated in this pre-test. The respondents consist of three ethnic groups, namely Malay, Iban, and Chinese. The purpose of this pre-test was to evaluate the quality of the questions and to be answered in terms of logically sequenced, comprehensibility, and average period. After completing the questionnaire, each respondent was asked to explain each question in the questionnaire as well as the response they choose. For non-Malay respondents whose mother tongue was not Malay language, they were enquired whether they were able to understand each statement clearly. For any unclear statement, the respondents were asked to provide the statement in their own words. Feedbacks from each respondent were obtained and recorded. Minor changes in the questionnaire had been made following the pre-test.

In reliability analysis, the Cronbach's alpha for each section was generally reliable. For part C, the Cronbach's alpha was 0.92 . For part $D$, the Cronbach's alpha were $0.83,0.80,0.81,0.73$, 0.76 and 0.83 for each of the respective subsections. For part $E$, the Cronbach's alpha was 0.67 . A reliability coefficient of 0.7 and above was considered as reliable instrument for survey research ${ }^{50}$.

\section{Data entry and analysis}

Collected data were checked and verified manually. Next, the data were entered into computer ${ }^{51}$ using Microsoft excel with a validation check. The raw data were imported to the analytic tool Statistical Package for Social Science (SPSS) version 22 for Windows ${ }^{52}$. The data were coded and verified for duplication before analysis.

Pearson's moment correlation was used to correlate perceived body image with BMI, selfesteem, body change strategy, and social network usage. A stepwise multiple linear regression analysis was done to determine the factors associated with perceived body image. The perceived body image was the dependent variable with continuous data. A standardised latent variable score with the mean ' 0 ' and standard deviation ' 1 ' was calculated. The gender was a dummy coded ' 1 ' as male and ' 0 ' as female. Firstly, skewed and outliers data were determined. Univariate and multivariate outliers were identified using Mahalanobis distance ${ }^{53}$, Cook's distance, and studentised residuals with \pm 2.0 standard deviation. After bivariate Pearson’s moment correlation, multicollinear variables were removed from the model. A total of 38 data were removed due to outliers. Age, gender, BMI, self-esteem, all six body change strategies' subsections, and social network usage were entered into the model. A p-value of less than 0.05 was considered statistically significant.

\section{Ethical issues}

Concerning the possible ethical issues related to this research, adolescents' participation in this research was voluntary and consented to by respective parents. The adolescents' identity and personal information were kept confidential to ensure that the adolescents' personal information was not disclosed. The ethics approval was obtained from the Faculty of Medicine and Health Sciences ethics committee, Universiti Malaysia Sarawak (Ref: UNIMAS/NC-21.02/03-02 Jld.4 (49)). 


\section{RESULTS}

Characteristics of respondents

A total of 318 adolescents participated in this study. Table 1 illustrates the characteristics of respondents. The respondents' mean age (SD) was 14.6 (2.7) years with a minimum age of 10 and the maximum age of 19 years. The gender of respondents was almost equal, with the male at $52.2 \%$ and female at $47.8 \%$. The majority of the respondents were of Malay ethnicity and Islam faith.

Perceived body image, body mass index, selfesteem, food practices and supplements, and body image strategies

Table 2 shows the mean (SD) for perceived body image, BMI, self-esteem, body change strategy, and social network usage. The mean (SD) for perceived body image was $3.63(0.83)$.

Table 1: Sociodemographic characteristics of the respondents $(n=318)$

\begin{tabular}{lccc}
\hline Variables & $\mathbf{n}$ & $\%$ & \multicolumn{1}{c}{ Statistics } \\
\hline Age in years & & & $\begin{array}{l}\text { Mean (SD) }=14.64(2.7) \text { years } \\
\text { Min=10, Max 19 }\end{array}$ \\
Gender & & & \\
$\quad$ Male & 166 & 52.2 & \\
$\quad$ Female & 152 & 47.8 & \\
Race & & & \\
$\quad$ Malays & 173 & 54.4 & \\
$\quad$ Non-Malay Bumiputras & 112 & 35.2 & \\
$\quad$ Chinese & 33 & 10.4 & \\
Religion & & & \\
$\quad$ Islam & 180 & 56.6 & \\
$\quad$ Christianity & 105 & 33.0 & \\
$\quad$ Buddhism & 30 & 9.4 & \\
$\quad$ Baha'i Faith & 3 & 0.9 & \\
\hline
\end{tabular}

Table 2: Mean distribution Perceived body image, body mass index, self-esteem, food practices and supplements and body image strategies

\begin{tabular}{lcccccc}
\hline Variables & $\begin{array}{c}\text { No. } \\
\text { Items }\end{array}$ & Mean & $\begin{array}{c}\text { Std } \\
\text { Deviation }\end{array}$ & Median & Min & Max \\
\hline Perceived Body Image & 10 & 3.63 & 0.87 & 3.50 & 1.0 & 5.0 \\
Body Mass Index & 10 & 20.4 & 5.54 & 19.5 & 11.2 & 51.9 \\
Self-esteem & 9 & 4.02 & 2.75 & 16.0 & 8 & 24 \\
Food Practices & 10 & 4.57 & 0.74 & 4.11 & 1 & 5 \\
Food Supplements & 9 & 4.09 & 0.75 & 4.80 & 2.6 & 5 \\
Strategies to lose weight & 9 & 4.12 & 0.70 & 4.22 & 1 & 5 \\
Strategies to increase weight & 6 & 4.10 & 0.80 & 4.17 & 1 & 5 \\
Strategies to increase muscle tone & 6 & 4.14 & 0.77 & 4.17 & 1 & 5 \\
Strategies to increase muscle size & & 2.15 & 1.66 & 2.00 & 0 & 7 \\
Social network usage & & & & & & \\
\hline
\end{tabular}

Factors affecting Perceived Body Image

Table 3 shows the analysis of stepwise multiple linear regression. For the final model, gender, $\mathrm{BMI}$, number of social network use, and strategies to increase weight had a potential impact on perceived body image with adjusted R-square $=0.162$. The ANOVA for the fourth model showed a statistically significant $[F(d f)=14.436(279)$; $\mathrm{p}<0.001]$. The analysis revealed that gender ( $20.2 \%$ contribution in the model) was the most important predictor of perceived body image, followed by strategies to increase weight $(16.1 \%$ contribution). However, the number of social networks used $(17.4 \%$ contribution) and $\mathrm{BMI}$ $(15.3 \%)$ had a negative effect on perceived body image $(p<0.01)$.

\section{DISCUSSION}

The current study found that the mean perceived body image score was 3.63 , which is higher as compared to previous studies in Malaysia ${ }^{44}$. In contrast, this value was similar to other countries' perceived body image level, such as New Zealand and Tonga. The higher mean value indicates that rural adolescents were satisfied with their body image as compared to Chinese-Malaysians. It should be noted that McCabe's studies only assessed Chinese-Malaysians who were staying in Peninsular Malaysia. As such, McCabe's study may not be representative of the whole of Malaysia. Nevertheless, this study used the original BIBCQ that consists of ten items for perceived body image, while McCabe et al. ${ }^{54}$ used a revised BIBCQ that only has five items. The use of different questionnaires may cause a discrepancy between these two studies among Malaysian adolescents. 
Table 3: Factors affecting Perceived Body Image: Stepwise multiple linear regression analysis

\begin{tabular}{|c|c|c|c|c|c|c|c|c|}
\hline \multirow{2}{*}{\multicolumn{2}{|c|}{ Model }} & \multirow[b]{2}{*}{ Unstd. B } & \multirow[b]{2}{*}{ SE } & \multirow[b]{2}{*}{ Std. Beta } & \multicolumn{2}{|c|}{$95.0 \% \mathrm{Cl}$ for $\mathrm{B}$} & \multirow[b]{2}{*}{$\begin{array}{l}\text { Correlations } \\
\text { Part }\end{array}$} & \multirow[b]{2}{*}{ Adj. $R^{2}$} \\
\hline & & & & & $\begin{array}{l}\text { Lower } \\
\text { Bound }\end{array}$ & $\begin{array}{l}\text { Upper } \\
\text { Bound }\end{array}$ & & \\
\hline \multirow[t]{2}{*}{1} & (Constant) & 0.373 & 0.088 & & 0.200 & 0.546 & & 0.072 \\
\hline & Social network & -0.161 & 0.034 & $-0.274^{* * *}$ & -0.227 & -0.094 & -0.274 & $(p<0.001)$ \\
\hline \multirow[t]{3}{*}{2} & (Constant) & 0.157 & 0.106 & & -0.051 & 0.365 & & \\
\hline & Social network & -0.153 & 0.033 & $-0.262^{* * *}$ & -0.219 & -0.088 & -0.261 & .109 \\
\hline & Gender & 0.378 & 0.107 & $0.200^{* * *}$ & 0.167 & 0.589 & 0.199 & \\
\hline \multirow[t]{4}{*}{3} & (Constant) & 1.013 & 0.274 & & 0.474 & 1.552 & & \\
\hline & Social network & -0.154 & 0.033 & $-0.263^{* * *}$ & -0.218 & -0.090 & -0.262 & 0.141 \\
\hline & Gender & 0.403 & 0.106 & $0.213^{* * *}$ & 0.196 & 0.611 & 0.212 & $(p<0.01)$ \\
\hline & BMI & -0.044 & 0.013 & $-0.188^{* *}$ & -0.070 & -0.018 & -0.188 & \\
\hline \multirow[t]{5}{*}{4} & (Constant) & 0.913 & 0.273 & & 0.376 & 1.450 & & \\
\hline & Social network & -0.137 & 0.033 & $-0.233^{* * *}$ & -0.201 & -0.072 & -0.229 & \\
\hline & Gender & 0.385 & 0.104 & $0.203^{* * *}$ & 0.179 & 0.590 & 0.202 & 0.162 \\
\hline & BMI & -0.041 & 0.013 & $-0.175^{* *}$ & -0.066 & -0.016 & -0.174 & $(p<0.01)$ \\
\hline & $\begin{array}{l}\text { Strategies to } \\
\text { increase weight }\end{array}$ & 0.173 & 0.062 & $0.157^{* *}$ & 0.051 & 0.295 & 0.153 & \\
\hline
\end{tabular}

For BMI, stepwise multiple linear regression analysis also found that BMI was one of the predictors for perceived body image. This finding was similar to other studies, whereby overweight and obese adolescents are found to be dissatisfied with their body image ${ }^{19,28}$. Adolescents are easily influenced by the media's portrayal of ideal body image, a thin body figure for females, and muscular body figures for males. Adolescents who do not have the ideal body figure would be dissatisfied with their body image, especially among those who are overweight or obese.

This study found no correlation between selfesteem and perceived body image. This finding was inconsistent with other studies whereby body image was correlated with self-esteem ${ }^{26,36,37}$. The lack of relationship between perceived body image and self-esteem might be associated with the cultural norm in the community, which emphasised integration among adolescents, thus leading to better self-esteem ${ }^{55}$.

This study explored the effect of body change strategies on perceived body image. The high mean value $(>4.00)$ for each body change strategies indicated that the adolescents were at low risk of participating in these body change strategies. The regression analysis found that only the use of strategies to increase weight had an impact on perceived body image. The positive correlation of this relationship indicated that adolescents who were at risk of practising strategies to increase weight were also dissatisfied with their body image. As strategies to increase weight have similar methods with other strategies such as changing eating habits and eating more, the outcome of these strategies would lead to increase body weight. This outcome may not be desirable among adolescents, thus leading to further body image dissatisfaction as well. Previous studies used body image satisfaction levels to predict which body change strategies may be used by adolescents to improve body image 56,57 . These studies did not examine the effect of body change strategies on perceived body image. As such, it was not possible to compare some of the findings in this study with previous studies. Further longitudinal studies are needed to explore these relationships for adolescents.

Regression analysis identified the number of social networks used as one of the predictors for perceived body image. Related studies found that social networks can cause body image dissatisfaction through social comparison with friends and celebrities 42,43 . Social networks provide a platform for users to share and view photos and videos. Adolescents may use these platforms to compare themselves with their friends or celebrities, leading to body image dissatisfaction ${ }^{58}$.

There were several limitations identified in this study. Firstly, the results obtained would not be generalisable as it was conducted in two districts of Sarawak. Secondly, this was a study crosssectional study; cause and effect relationship could not be determined as both the independent (self-esteem, personal characteristics) and dependant variables (perceived body image) were measured in the same timeframe. Lastly, respondents were required to answer all the questions; they may have responded to each question without going into depth ${ }^{59}$.

\section{CONCLUSION}

In conclusion, the body image satisfaction level was higher among adolescents in the rural area of Samarahan and Asajaya districts as compared with other studies in Malaysia. Despite the lower level of body image dissatisfaction, it can still be a threat to adolescents' health. The current research also concluded that gender, BMI, 
engaging in strategies to increase weight, and social network usage contribute to adolescents' perceived body image. Lastly, this study did not find any significant relationship between perceived body image and self-esteem, although various studies proved otherwise. Public health practitioners could use this study's results to improve adolescents' health services in relation to perceived body image through further public health research, practices, and health policies.

\section{Conflict of interest}

The authors declare no potential conflict of interest.

\section{ACKNOWLEDGMENTS}

We thankfully acknowledge the adolescents who voluntarily participate in this study as well as the parents who consented to their participation. Our sincere gratitude to UNIMAS for the support in conducting the research.

\section{Funding}

Self-funded.

\section{REFERENCES}

1. Grogan S. Body Image: Understanding Body Dissatisfaction in Men, Women and Children: Third Edition.; 2017.

2. Thompson K. The (mis)measurement of body image: ten strategies to improve assessment for applied and research purposes. Body Image. 2004;1(1):7-14. doi:10.1016/S1740-1445(03)00004-4

3. Cash T. Multidimensional Body-Self Relations Questionnaire (MBSRQ). In: Wade T, ed. Encyclopedia of Feeding and Eating Disorders. Springer Singapore; 2016:1-4. doi:10.1007/978-981-287-0872_3-1

4. Markey C. Invited Commentary: Why Body Image is Important to Adolescent Development. J Youth Adolesc. 2010;39(12):1387-1391. doi:10.1007/s10964-010-9510-0

5. Clay D, Vignoles V, Dittmar H. Body Image and Self-Esteem Among Adolescent Girls: Testing the Influence of Sociocultural Factors. J Res Adolesc. 2005; 15:451-477. doi:10.1111/j.1532-7795.2005. 00107.x

6. Bratland-Sanda S, Sundgot-Borgen J. Symptoms of eating disorders, drive for muscularity and physical activity among Norwegian adolescents. Eur Eat Disord
Rev.

doi:10.1002/erv.1156

7. Hoffmann S, Warschburger P. Weight, shape, and muscularity concerns in male and female adolescents: Predictors of change and influences on eating concern. Int J Eat Disord. 2017;50(2):139-147. doi:10.1002/eat.22635

8. Jankauskiene R, Baceviciene M. Body Image Concerns and Body Weight Overestimation Do Not Promote Healthy Behaviour: Evidence from Adolescents in Lithuania. Int J Env Res Public Health. 2019;16(5). doi:10.3390/ijerph16050864

9. McCreary D, Sasse D. An exploration of the drive for muscularity in adolescent boys and girls. J Am Coll Health. 2000;48(6):297-304. doi:10.1080/07448480009596271

10. Zhang $Y$, Wang $Z$, Wang $M$, Xie L. Prevalence of thinness among children and adolescents in Shandong, China. Eur J Nutr. 2016;55(2):809-813. doi:10.1007/s00394-015-0902-5

11. Mooney E, Farley H, Strugnell C. A qualitative investigation into the opinions of adolescent females regarding their body image concerns and dieting practices in the Republic of Ireland (ROI). Appetite. 2009;52(2):485-491. doi:10.1016/j.appet.2008.12.012

12. Cheah WL, Hazmi H, Chang CT. Disordered eating and body image issues and their associated factors among adolescents in urban secondary schools in Sarawak, Malaysia. Int $J$ Adolesc Med Health. 2017;29(2). doi:10.1515/ijamh-2015-0044

13. Farah Wahida Z, Mohd Taib MN, Abu Saad $\mathrm{H}$. Physical activity, eating behaviour and body image perception among young adolescents in Kuantan, Pahang, Malaysia. Malays J Nutr. 2011;17(3):325-336.

14. Japil A, Mustapha M, Guan TE. Body Dissatisfaction among Male and Female Adolescents. 2018;1:1-7.

15. Khor GL, Mohd Shariff Z, Phan YY, Ang M, Maznah B, Abdul Karim N. Perceptions of body image among Malaysian male and female adolescents. Singapore Med J. 2009;50(3):303-311. 
16. Omar Dev R, Permal V, Omar Fauzee MS. Rural urban differences in body image perception, body mass index and dieting behaviour among Malay Adolescent Malaysian schoolgirls. Eur J Sci Res. 2009;34:69-82.

17. Soo KL, Mohd Shariff Z, Mohd Taib MN, Abu Samah B. Eating behaviour, body image, and self-esteem of adolescent girls in Malaysia. Percept Mot Ski. 2008;106(3):833-844. doi:10.2466/pms.106.3.833-844

18. Maezono J, Hamada S, Sillanmaki L, et al. Cross-cultural, population-based study on adolescent body image and eating distress in Japan and Finland. Scand J Psychol. 2019;60(1):67-76. doi:10.1111/sjop. 12485

19. Allen D, Belcher H, Young A, Gibson LW, Colantuoni E, Trent M. BMI, Body Image, Emotional Well-Being and Weight-Control Behaviors in Urban African American Adolescents. Int $J$ Child Health Nutr. 2016;5(3):55-104.

20. del Mar Bibiloni M, Pich J, Pons A, Tur J. Body image and eating patterns among adolescents. BMC Public Health. 2013;13:1104. doi:10.1186/1471-2458-131104

21. Cruz-Saez S, Pascual A, Wlodarczyk A, Echeburua E. The effect of body dissatisfaction on disordered eating: The mediating role of self-esteem and negative affect in male and female adolescents. J Health Psychol. Published online August 11, 2018:1359105317748734. doi:10.1177/1359105317748734

22. Gaddad P, Pemde HK, Basu S, Dhankar M, Rajendran S. Relationship of physical activity with body image, self esteem sedentary lifestyle, body mass index and eating attitude in adolescents: A crosssectional observational study. J Fam Med Prim Care. 2018;7(4):775-779. doi:10.4103/jfmpc.jfmpc_114_18

23. Lee J, Lee Y. The association of body image distortion with weight control behaviors, diet behaviors, physical activity, sadness, and suicidal ideation among Korean high school students: a cross-sectional study. BMC Public Health. 2016;16:39. doi:10.1186/s12889-0162703-z

24. Mitchison D, Hay P, Griffiths S, et al. Disentangling body image: The relative associations of overvaluation, dissatisfaction, and preoccupation with psychological distress and eating disorder behaviors in male and female adolescents. Int $J$ Eat Disord. 2017;50(2):118-126. doi:10.1002/eat.22592

25. Schuck K, Munsch S, Schneider S. Body image perceptions and symptoms of disturbed eating behavior among children and adolescents in Germany. Child Adolesc Psychiatry Ment Health. 2018;12:10. doi:10.1186/s13034-0180216-5

26. Wichstrøm L, von Soest T. Reciprocal relations between body satisfaction and self-esteem: A large 13-year prospective study of adolescents. $J$ Adolesc. 2016;47:16-27.

doi:10.1016/j.adolescence.2015.12.003

27. Kaewpradub N, Kiatrungrit K, Hongsanguansri S, Pavasuthipaisit $C$. Association Among Internet Usage, Body Image and Eating Behaviors of Secondary School Students. Shanghai Arch Psychiatry. 2017;29(4):208-217. doi:10.11919/j.issn.1002-0829.216092

28. Rezali FW, Chin YS, Mohd Yusof BN. Obesity-related behaviors of Malaysian adolescents: a sample from Kajang district of Selangor state. Nutr Res Pract. 2012;6(5):458-465.

doi:10.4162/nrp.2012.6.5.458

29. World Health Organization. Body mass index - BMI. Accessed May 28, 2020. http://www.euro.who.int/en/healthtopics/disease-prevention/nutrition/ahealthy-lifestyle/body-mass-index-bmi

30. Kantanista A, Krol-Zielinska M, Borowiec $\mathrm{J}$, Osinski W. Is underweight Associated with more Positive Body Image? Results of a Cross-Sectional Study in Adolescent Girls and Boys. Span J Psychol. 2017;20:E8. doi:10.1017/sjp.2017.4 
31. Abdul Latiff A, Muhamad J, Abdul Rahman R. Body image dissatisfaction and its determinants among young primaryschool adolescents. J Taibah Univ Med Sci. $\quad$ 2018;13(1):34-41. doi:10.1016/j.jtumed.2017.07.003

32. Canpolat BI, Orsel S, Akdemir A, Ozbay H. The relationship between dieting and body image, body ideal, self-perception, and body mass index in Turkish adolescents. Int $J$ Eat Disord. 2005;37(2):150-155. doi:10.1002/eat.20081

33. Rosenberg $M$. The association between self-esteem and anxiety. J Psychiatr Res. 1962;1:135-152. doi:10.1016/00223956(62) $90004-3$

34. Makinen $M$, Puukko-Viertomies L-R, Lindberg $N$, Siimes $M$, Aalberg V. Body dissatisfaction and body mass in girls and boys transitioning from early to midadolescence: additional role of selfesteem and eating habits. BMC Psychiatry. 2012;12:35. doi:10.1186/1471-244X-12-35

35. Singh M, Ashok L, Binu VS, Parsekar S, Bhumika TV. Adolescents and Body Image: A Cross Sectional Study. Indian J Pediatr. 2015;82(12):1107-1111. doi:10.1007/s12098-015-1768-5

36. Morin A, Maiano C, Marsh H, Janosz M, Nagengast B. The Longitudinal Interplay of Adolescents' Self-Esteem and Body Image: A Conditional Autoregressive Latent Trajectory Analysis. Multivar Behav Res. 2011;46(2):157-201. doi:10.1080/00273171.2010.546731

37. Paxton S, Neumark-Sztainer D, Hannan P, Eisenberg M. Body dissatisfaction prospectively predicts depressive mood and low self-esteem in adolescent girls and boys. J Clin Child Adolesc Psychol. 2006;35(4):539-549. doi:10.1207/s15374424jccp3504_5

38. Tiggemann M. Body dissatisfaction and adolescent self-esteem: prospective findings. Body Image. 2005;2(2):129-135. doi:10.1016/j.bodyim.2005.03.006

39. Paxton S, Eisenberg $M$, Neumark-Sztainer D. Prospective predictors of body dissatisfaction in adolescent girls and boys: A five-year longitudinal study. Dev Psychol. 2006;42:888-899.

doi:10.1037/0012-1649.42.5.888

40. Oxford Learners Dictionaries. Socialnetworking. Accessed August 14, 2020. https: / /www.oxfordlearnersdictionaries. $\mathrm{com} /$ definition/english/socialnetworking?q=social+networking

41. Derenne J, Beresin E. Body Image, Media, and Eating Disorders-a 10-Year Update. Acad Psychiatry J Am Assoc Dir Psychiatr Resid Train Assoc Acad Psychiatry. 2018;42(1):129-134. doi:10.1007/s40596017-0832-z

42. de Vries D, Peter J, de Graaf H, Nikken P. Adolescents' Social Network Site Use, Peer Appearance-Related Feedback, and Body Dissatisfaction: Testing a Mediation Model. J Youth Adolesc. 2016;45(1):211224. doi:10.1007/s10964-015-0266-4

43. Ho S, Lee E, Liao Y. Social Network Sites, Friends, and Celebrities: The Roles of Social Comparison and Celebrity Involvement in Adolescents' Body Image Dissatisfaction. Soc Media Soc. 2016;2(3):2056305116664216. doi:10.1177/2056305116664216

44. McCabe M, Ricciardelli L. Body image and body change techniques among young adolescent boys. Eur Eat Disord Rev. 2001;9:335-347. doi:10.1002/erv.389

45. Moore D. Body image and eating behavior in adolescent girls. Am $J$ Child. 1988;142(10):1114-1118.

doi:10.1001/archpedi.1988.02150100108 038

46. Mellor D, Ricciardelli L, McCabe M, Yeow J, Mamat N, Hapidzal N. Psychosocial Correlates of Body Image and Body Change Behaviors Among Malaysian Adolescent Boys and Girls. Sex Roles. 2010;63:386-398. doi:10.1007/s11199010-9812-4

47. Department of Statistics Malaysia. Population Distribution and Basic Demographic Characteristics.; 2010.

48. Ricciardelli L, McCabe M. Psychometric evaluation of the Body Change Inventory: An assessment instrument for adolescent 
boys and girls. Eat Behav. 2002;3(1):4559. doi:10.1016/S1471-0153(01)00044-7

49. Li L, Yn L, Huey T, et al. Construct Validity and Reliability of Rosenberg Self-Esteem Scale-Malay (RSES-M) Among Upper Secondary School Students in Malaysia. Malays J Med Health Sci. 2019;15(2):3238.

50. Hair J, Anderson R, Babin B, Black W. Multivariate Data Analysis. 7th edition. Pearson Education Inc.; 2009.

51. Cooper J. Introduction to Data Management. Statistical Associates Publishers; 2015. http://www.statisticalassociates.com/da tamanagement.pdf

52. IBM SPSS. IBM SPSS Statistics for Windows. IBM SPSS; 2013.

53. Sharma A. Understanding Mahalanobis Distance And Its Use Cases. Analytics India Magazine. Published July 10, 2018. Accessed June 10, 2019. https: / / www.analyticsindiamag.com/und erstanding-mahalanobis-distance-and-itsuse-cases/

54. McCabe M, Fuller-Tyszkiewicz M, Mellor D, Ricciardelli L, Skouteris H, Mussap A. Body satisfaction among adolescents in eight different countries. J Health Psychol. 2011;17:693-701. doi:10.1177/1359105311425274
55. Uba I, Yaacob SN, Juhari R, Talib MA. Effect of Self-Esteem on the Relationship between Depression and Bullying among Teenagers in Malaysia. Asian Soc Sci. 2010;6(12):p77. doi:10.5539/ass.v6n12p77

56. McCabe M, Ricciardelli L, Holt K. Are there different sociocultural influences on body image and body change strategies for overweight adolescent boys and girls? Eat Behav. 2010;11(3):156-163. doi:10.1016/j.eatbeh.2010.01.005

57. McCabe M, Ricciardelli L. Sociocultural influences on body image and body changes among adolescent boys and girls. $J$ Soc Psychol. 2003;143(1):5-26. doi: $10.1080 / 00224540309598428$

58. Santarossa S, Woodruff S. \#SocialMedia: Exploring the Relationship of Social Networking Sites on Body Image, SelfEsteem, and Eating Disorders. Soc Media Soc. $\quad 2017 ; 3(2): 2056305117704407$. doi: $10.1177 / 2056305117704407$

59. Nederhof A. Methods of coping with social desirability bias: A review. Eur J Soc Psychol. 1985;15(3):263-280. doi:10.1002/ejsp.2420150303 